\title{
Process of modelling the freight wagon multibody system and analysing its dynamic properties by means of simulation computations
}

\author{
Ján Dižo ${ }^{1, *}$, Miroslav Blatnický ${ }^{1}$ and Alfréd Pavlík ${ }^{1}$ \\ ${ }^{1}$ University of Žilina, Faculty of Mechanical Engineering, Department of Transport and Handling Machines, Univerzitná 8215/1, 010 26, \\ Žilina, Slovak Republic
}

\begin{abstract}
Computational modelling and simulations are nowadays widely used for design of railway vehicles, analysing and assessment of their dynamic properties and also for detection and prediction of the mechanism of deterioration and sources of damages. Therefore it is necessary to develop the adequate virtual model of an analysed railway vehicle as well as a track. For these purposes many simulations software packages are developed. In these computational programs a railway vehicle is modelled as a mechanical system usually consists of many bodies called a multibody system. In this paper the process of computational modelling of a freight wagon multibody system is outlined. Moreover, there are presented also results of dynamic simulation of a freight wagon running on a real track section. The analysed intermodal freight wagon was equipped with Y25 bogie. The freight wagon model, simulation analyses and ride properties evaluation were performed by means of a commercial simulation program.
\end{abstract}

\section{Introduction}

The design of a railway vehicle has to meet strict requirements for its commissioning in real operation conditions. Production and operation of railway vehicles is closely linked to economic factors. Results of simulation calculations significantly contribute to the estimation and prediction of railway vehicles behaviour. Implementation of virtual reality tools requires creating a representative virtual model of a railway vehicle, which sufficiently and accurately reflects its essential mechanical properties. Simulations of railway vehicles can be performed using some commercial software working with a railway vehicle model as a system of mass points, which represent individual railway vehicle body interconnected by joints, couplings, constraints etc.

The issue of investigation of railway vehicles dynamic behaviours is still current especially in terms of development of new railway vehicles and their approval in operation, analysis of the interaction of a railway vehicle and track as well as prediction of railway vehicles behaviour running on a track according to the changes of a railway vehicle design or a track.

\section{Modelling the freight wagon multibody system}

The production of a new railway vehicle, i. e. also a freight wagon, is consists of: the design of a prototype, development phase, optimization of a freight wagon model, construction of a freight wagon, verification and validation of a freight wagon. The development phase of a new railway vehicle implies not only static analysis but also dynamic analysis in order to obtain data about its dynamic properties.

Phases of development and optimization of railway vehicles use different ways of analysing the dynamic and ride properties of a railway vehicle. Computational simulations of a railway vehicle running deal with dynamic of railway vehicle multibody system (its reaction on a track excitation) [1-5].

After the process of preparing and creating the railway vehicle multibody system can be performed with it a multibody simulation. What is the multibody simulation?

The multibody simulation, also known as multibody system simulation, is used for prediction and optimisation of dynamic behaviour of any type of multibody system by solving the equations of motion $[6$, 7]. The name multibody can refer to a wide range of systems, thus of course, a railway vehicle mechanical system.

The bodies of a railway vehicle multibody system are linked by means of joints and other kinematic constraints, which allow certain motions and restrict others. Bodies can be rigid or flexible. The system is completed by excitation elements and sensors for measuring the desired outputs [8]. Dynamic properties are described by motions of a railway vehicle system due to the applied forces and the inertia characteristics of bodies, i.e. their mass, moments of inertia and position of the centre of gravity.

\footnotetext{
Corresponding author: jan.dizo@,fstroj.uniza.sk
} 
The railway vehicle multibody system approach, with the development of computer technology, is clearly an added value in the analysis and design of railway vehicle [9].

Within a railway vehicle simulation the contact mechanics entries into calculation as well [10]. Analysis of the contact mechanics is used for the investigation of the wheel/rail phenomenon conditions [11, 12], such as creep forces, stress distribution, rolling contact fatigue, wear etc. $[13,14]$.

Computer modelling the railway vehicles allows for a user to test out various situations without spending the time, money and use of equipment to test them on a track $[15,16]$. Modelling can predict conditions of derailment situation, i. e. what speed derailment of wheel/rail can occur at or under which conditions it may be prevented [17-19].

In the field of modelling a railway vehicle, during last four decades, computer hardware and software are highly developed and used to simulate the dynamic relations. This simulation programs help universities, railway organisation and train manufacturing to deal with own related issues and project such as reducing the number of (expensive) field measurements [20, 21], parameter studies on the dynamic behaviour of the railway vehicle, predicting and reducing the time and cost of increasing the railway vehicle performance like increasing speed of the vehicle, increasing axle load.

Using modern computer software there is possible to carry out realistic simulations of dynamic behaviours of railway vehicles. The theoretical basis of the mathematical modelling used are mature and reliable, therefore current simulations tools are often originally written by research institutes to powerful, validated and user-friendly software.

There have been developed several computer software to help engineers simulating the dynamic properties of railway vehicles. These multibody tools have been created to have more user friendly environments with more graphical features, animations and simpler coding. All railway simulation tools, more or less, have the same procedure. Simpack, VI-Rail (based on Adams/Rail), Universal Mechanism and also Vampire, Nucars and Gensys are recently most used software in the field of railway vehicle multibody simulations [22-24].

The setting up a mechanical model of a railway vehicle is the first step in every railway vehicle multibody simulation. Such a model constitutes the base for its mathematical description using the equations of motion, obtained with the aid of physical principles and laws (Newton's law, etc.). The multibody system approach is the powerful and the most widely used method for this procedure, especially if the vehicle's running behaviours have to be analysed.

As it was mentioned above, a railway vehicle multibody system consists of rigid bodies (eventually flexible body) interconnected via massless force elements, joints or similar constraints. Due to relative motions of the system's bodies, force elements generate additional forces and torques. Springs, dampers or actuators combined in primary and secondary suspension of a railway vehicle are typical examples of such force elements.

To take the flexibility of lightweight structures into account the interface between the multibody software and Finite Element software has been implemented in principle into every multibody software.

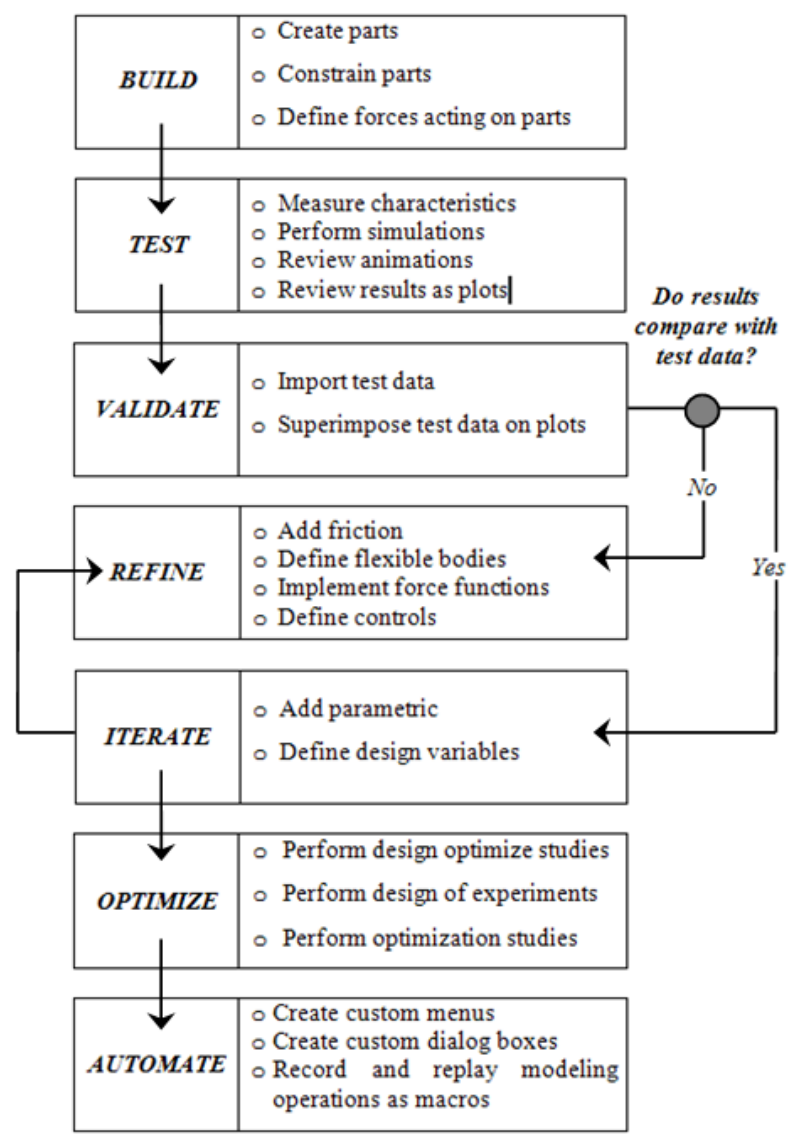

Fig. 1. Process of modelling and simulation of a railway vehicle

Modelling of an entire railway vehicle and a railway track system is divided into three main parts:

- vehicle model,

- track model

- wheel/rail contact.

In view of a railway vehicle system and track subsystem, forces generated by wheel/rail contact can be regarded as external forces. The excitation of vehicle and track leads to motions. The corresponding kinematic quantities are fed back to the wheel/rail contact.

With the advent of powerful computers simulation of complex mechanical system has become a real possibility. The railway vehicle computational model can be constructed and run on typical or measured track in a virtual environment and a wide range of possible designs or parameter changes can be investigated.

Inputs to a railway vehicle multibody system are usually considered in each wheelset. Typical inputs are vertical and lateral track irregularities and deviations in gauge and cross level.

Outputs from the model can be set up to provide accurate predictions of the dynamic behaviour of a railway vehicle and its interaction with a track. 
The rail transport remains the most cost effective method for moving freight between two locations connected by land. This is due to the low energy loss of metal on metal contact between wheels and rail.

\subsection{The multibody model of a freight wagon}

The typical freight wagon model consists of three main subsystems: the body of wagon, the front bogie and the rear bogie. The body of a freight wagon, bogie frames and wheelsets are dominating body components. They represent main vehicle mass. When the body of wagon, bogie frames, as well as wheelsets are treated as rigid bodies they are defined by their mass-inertia characteristics (mass, moments of inertia and the position of the centre of gravity) and by the relative position of the bogies with respect to the body of wagon itself [25]. Each rigid body has six degrees of freedom (three translations and three rotations). In some cases of a freight wagon running simulation the structural flexibility of a body is necessary to consider.

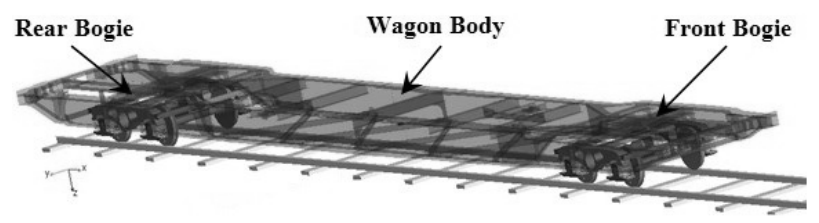

Fig. 2. The virtual model of an intermodal freight wagon

All bodies of a wagon are connected by springs and dampers which form primary and secondary suspension. Primary suspension is used to the connection between the wheelset and the bogie frame. The secondary suspension is used to the connection between the bogie and the body of wagon. In case of the modelled Y25 bogie the secondary suspension is consists of the centre pivot and two sidebearers.

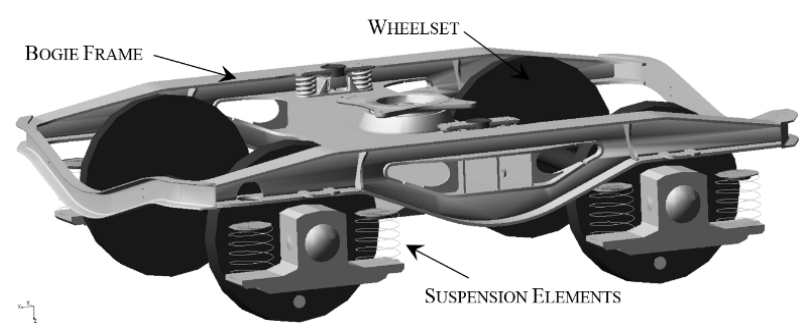

Fig. 3. The virtual model of the Y25 freight wagon bogie

\subsubsection{Wagon body}

The body of wagon usually holds main mass of a freight wagon. The mass properties of the body of wagon structure are not difficult to calculate: CAD model or finite (FE) analysis can give the mass, centre of gravity position and inertia moments quite easily.

In the most applications there is important to consider the structural flexibility of wagon body. In railway application dynamics simulation it is desirable to represent the structural flexibility of wagon body by only a limited number of degrees of freedom in addition to the six rigid body degrees of freedom (longitudinal, lateral, vertical, roll, pitch and yaw motions).

\subsubsection{Wagon bogie}

When it comes to the bogie frame modelling we should first keep in mind that the most common bogie type worldwide, the three-piece bogie, consist of three bodies and not only of a single bogie frame body. For a bogie frame, seen as a one-piece metal structure, the assumption of essentially rigid body behaviour is fair in most applications. Sometimes the torsional flexibility about a longitudinal axis, is considered representing an improved negotiation of twisted tracks. The bogie flexibility can be determined through finite element analysis [26] and may be represented in the freight wagon multibody simulation by a limited set of eigenmodes of free frame body. Such analysis can also give the mass and inertia moments of the bogie frame $[27,28]$.

\subsubsection{Wheelset}

A plain wheelset normally consists of one solid unit with two wheels on a common wheel axle. The wheel diameter is often $0.7 \mathrm{~m}$ to $1.0 \mathrm{~m}$. The axle diameter is usually $0.15 \mathrm{~m}$ to $0.20 \mathrm{~m}$. A typical mass for a plain wheelset is $1,000 \mathrm{~kg}$ to $1,500 \mathrm{~kg}$. Additional mass can be introduced through brake discs, mounted on the axle or wheels and traction gear. The axle boxes also add some mass but they should not be considered in calculating the wheelset pitch inertia moment. In fact, they are created as separate bodies in the modelling. Wheelsets are often modelled as rigid bodies, but wheel axle flexibility may affect the vehicle/track interaction.

\subsubsection{Suspension elements}

In our case, suspension components in freight wagons are coil spring in combination with friction dampers. They play important roles in reducing bogie frame and wagon body accelerations as well as dynamic wheel/rail forces. Bump stop and antiroll bars may therefore be introduced to mitigate such problems, the bars also reducing quasistatic lateral acceleration components although their man task is to transfer longitudinal forces between bogie and wagon body during acceleration or retardation. Some freight wagons are equipped with the friction damper. The most common friction model is that suggested by Coulomb's law. For a one-dimensional case such a model in series with a linear spring, which together has a linear spring in parallel, produces a resulting force - displacement.

\subsection{The multibody model of a track}

Nominal geometry (track layout), track flexibility as well as track irregularities must be modelled and described. A simple moving track model for lateral, vertical and roll flexibilities of the track is shown on Fig. 6. 
Such a simple model may be sufficient for analysis of the freight wagon interaction with the track. Stiffness and damping may have linear or nonlinear characteristics. Actual numerical data reflect the track construction, i.e. type of rails, fastenings, rail pads, sleepers and ballast, as well as freight wagon axle load. The track flexibility will, above all, influence track forces, but under certain circumstances lateral dynamic stability will also be affected.

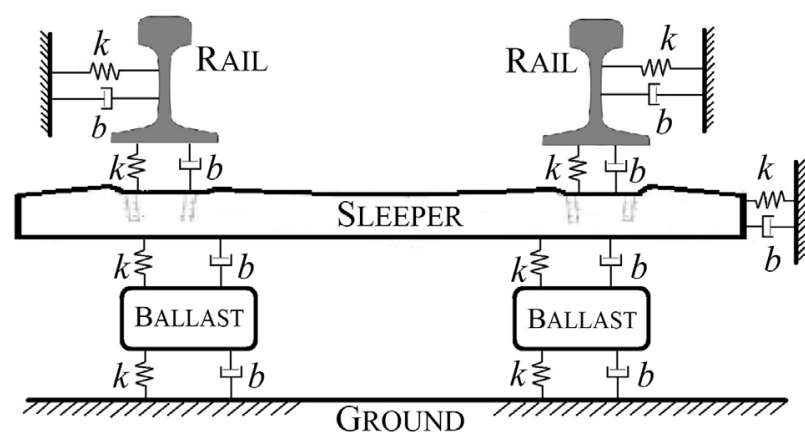

Fig. 4. Example of a track model

The nominal track geometry (layout) is defined by circular curve radii and lengths, lengths and types of transition curves, track cants, etc.

Track irregularities are normally given as lateral and vertical deviations of the track centreline (from nominal geometry) and by deviations in track cant and track gauge. It is important, track irregularities are representative for a longer section of track and they are also representative of the worst condition to be considered. A statistical analysis of track data is, therefore, very often needed.

\subsection{The wheel/rail contact model}

The crucial importance for the dynamic interaction between freight wagon and track has the characteristics of wheel/rail contact.

The contact functions are usually calculated in the PreProcessor program. The wheel and rail geometry, rail inclination, track gauge and wheelset flange spacing are the main inputs parameters.

The wheel-rail element always describes kinematics of one wheel relative to one rail. The wheel/rail contact is actually a complex and imperfect link. There are several approaches for the wheel/rail contact calculation used in commercial software.

The Wheel/rail contact defines, how the tangential forces and tangential torque for the contact patches are calculated. The wheel/rail contact search can be separated into three steps:

- identification of the contact patch locations, sizes and shapes, then for each contact patch that has been found:

- determination of the normal contact force,

- determination of the tangential contact forces and the tangential torque.

These steps may be executed separately or combined. The main input to most wheel/rail tangential force and torque calculation methods are the longitudinal $(x)$, lateral $(y)$ and spin (about $z$ ) creepages. The outputs ate the longitudinal and lateral tangential forces and sometimes the tangential torque [29-31].

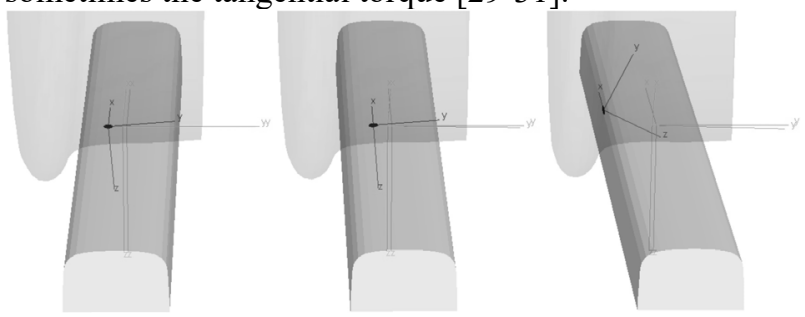

Fig. 5. Contact reference point location and coordinate system orientation for different yaw angle

\section{Analysis of ride properties of a freight wagon running on a track}

There are certain criteria for the railway vehicle assessment. One of the criteria for the assessment of the curving safety is the derailment quotient assessment. The derailment quotient is the guiding force and vertical force ratio. The derailment quotient limit value depends on a curve radius. The limit value is valid 0.8 for the curves of $\mathrm{R}>250 \mathrm{~m}$ on the length of $2 \mathrm{~m}$ and for smaller radii and for superelevation ramp 1.2. All requirements that railway vehicles must meet for the operation inclusion are referred in the relevant standard and regulations [32].

For purposes of dynamical analysis we have created the multibody model of a freight wagon, which is designed for intermodal transport representing current efficient solution of transport system [33, 34]. In our research we have chosen real track section in Slovakia for a freight wagon simulation analysis considering available important parameters. There are sections with different curve radii and the resulting section of the transmission curve and superelevation ramp on this track. It has been suitable for performing dynamic analysis and the derailment quotient assessment.

The total track length almost $6000 \mathrm{~m}$. There are three right curves and four left curves on this track (seven curves total). The horizontal profile of a track is shown in Fig. 6.

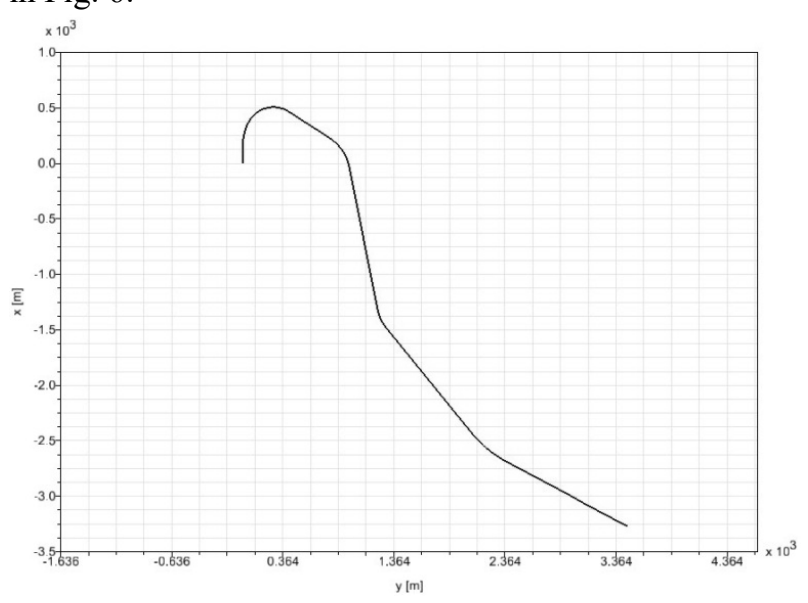

Fig. 6. The horizontal profile of a real track section 
For wheels of wagon the S1002 rail profile was chosen. The track model was created by two rails with the UIC60 profile and with inclination of 1:40. There were considered measured track irregularities prescribed by discrete form.

There were used following input parameters:

- the tare wagon model and the loaded wagon model,

- the general wheel/rail contact model,

- the real track section track model.

During a freight wagon testing the most attention was focused on the assessment of:

- lateral wheel forces $(Y)$,

- vertical wheel forces $(Q)$,

- derailment quotient $(Y / Q)$.

The tested freight wagon for both loading conditions has run on the track at the constant speed of $60 \mathrm{~km} / \mathrm{h}$. It means, the wagon has travelled the determined distance for $352 \mathrm{~s}$. For the evaluated ride properties the sample frequency of $160 \mathrm{~Hz}$ was chosen.

Output signals of the evaluated parameters in the wheel/rail contact area are marked according graphics in the Fig. 7.

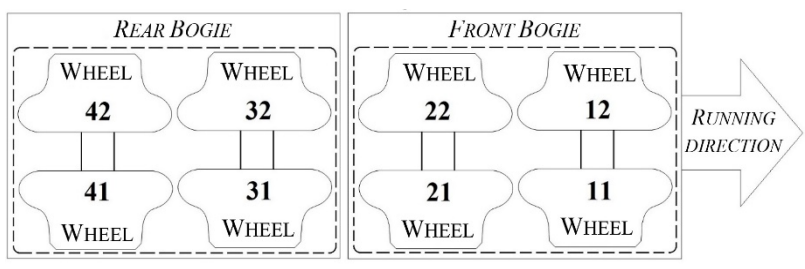

Fig. 7. Positions of output signals on wagon bogie
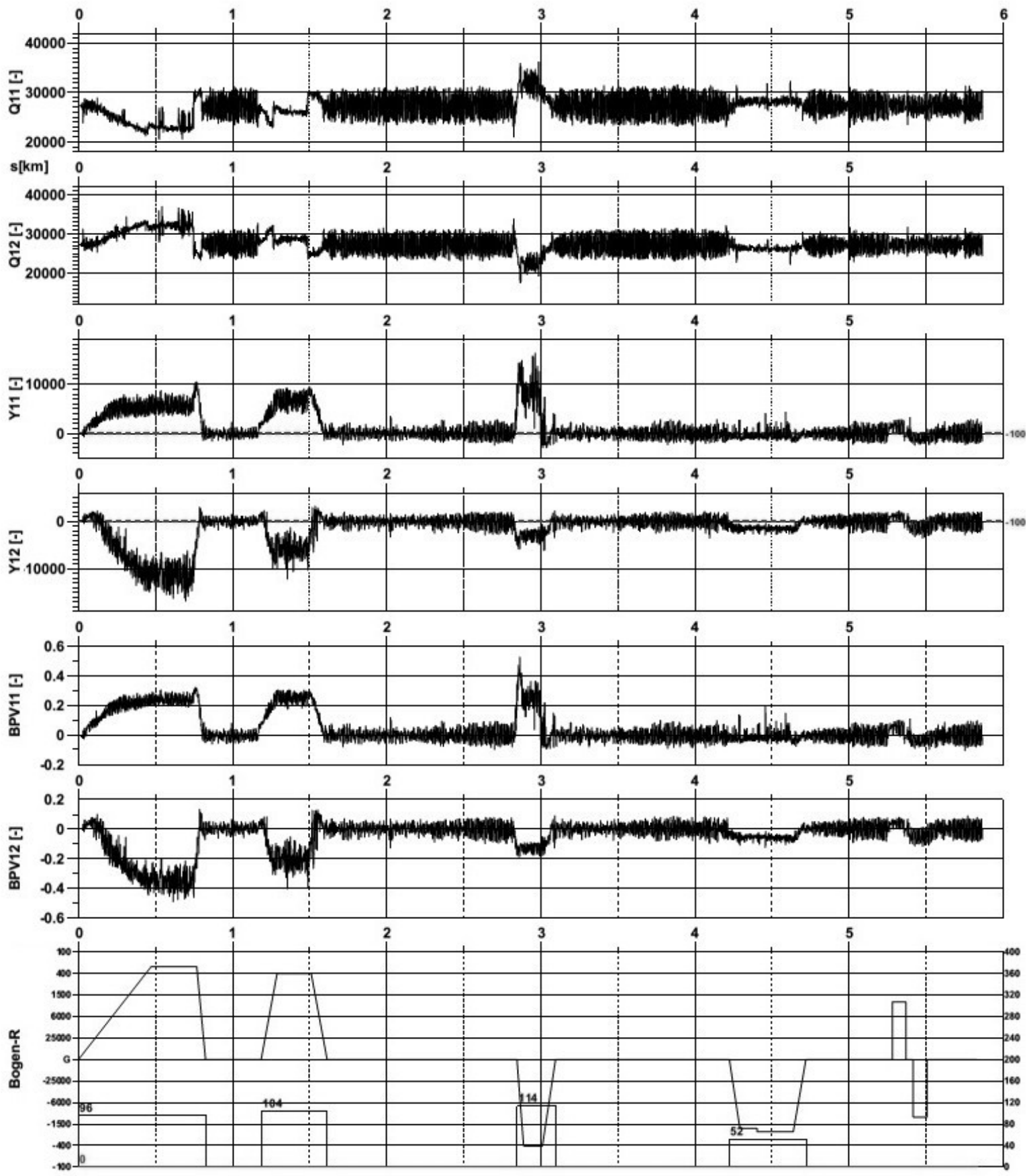

Fig. 8. Evaluation of selected outputs quantities for the tare freight wagon 

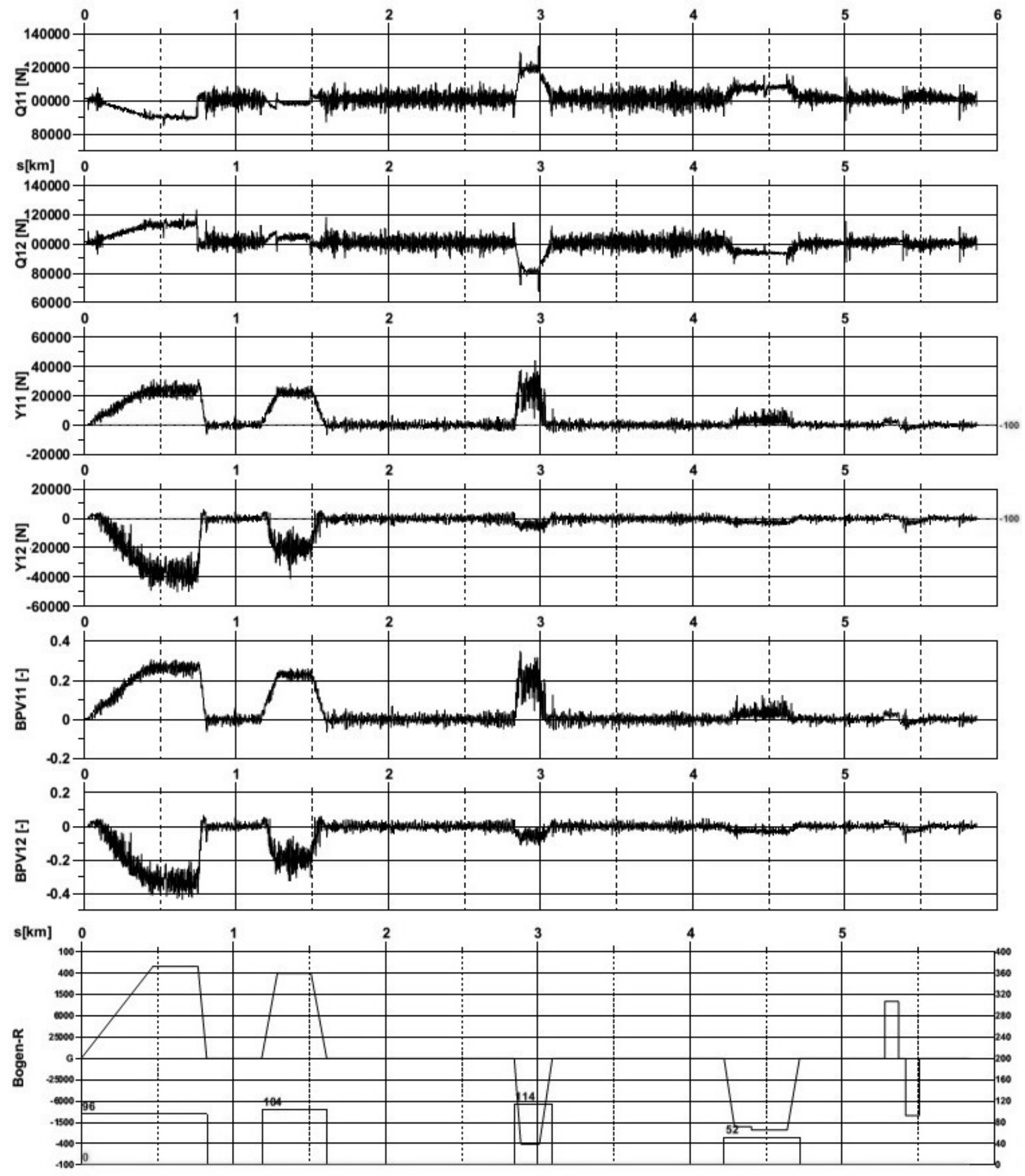

Fig. 9. Evaluation of selected outputs quantities for the loaded freight wagon

Results of dynamic analyses are shown in Fig. 8 and Fig. 9. In these cumulative graphs the comparison of comprehensive values of results are shown. These graphs include seven parts. The vertical forces are in the first and second parts, lateral forces in the third and fourth parts. Waveforms of the derailment quotients are outlined in the fifth and sixth parts and the track curvature is in the last (seventh) part. The larges values of lateral forces were achieved on the first axle of the front bogie, on the guiding wheel.
From waveforms of the vertical forces of the tare wagon (Fig 8) and the loaded wagon (Fig. 9) we can see, when the wagon is entering a curve, the vertical forces and the lateral forces are significantly increasing. The force values depend on the wagon weight.

The irregularities cause excitation of a freight wagon mechanical system. The irregularities were created on both rails in the $y$ (lateral) direction and in the $z$ (vertical) directions. When comparing vertical forces for tare and loaded wagon can we see the larger damping of these forces occur in the case of the loaded wagon running. 
This is because of the construction friction dampers used in the freight Y25 bogies, which are characterized by the friction force dependent on the load of a wagon.

For the derailment quotient assessment we came out again from the waveforms in Fig. 8 and Fig. 9. The greatest values of the derailment quotient reach the guiding wheel for the tare state, namely $Y / Q=0.485$. In case of the loaded state of the wagon the greatest value $\mathrm{Y} / \mathrm{Q}=0.405$ was identified. Observed values indicate, that the greatest $\mathrm{Y} / \mathrm{Q}$ ratio (the worst ride properties) was achieved on the guiding wheel of the wagon. This ratio is changing inversely with the wagon load (or axleload). It follows the worst risk of overriding the flange occurs, when the tare wagon is running in a curve.

\section{Conclusion}

At present, railway vehicle dynamics constitutes a significant and indispensable part of railway vehicle engineering. During the design period a prognosis of the running characteristics can be carried out with the aid of computer simulations. This enables reduction in the extent of the test and shortening of the vehicle design period.

The development of software tools for simulation of dynamic behaviour of railway vehicle on track has grown with the development of computing power. Software are now combined into a number of powerful and reliable computer simulation packages and improvements have also been made in modelling the components of vehicle/track systems.

The vehicle dynamic analysis represents a complex issue utilizing methods of mechanics, material engineering, engineering technology, mathematic applied into the railway vehicles area. Simulations represent a robust way, through which we can get adequate information resulting from increasing railway transport requirements.

In this paper ride properties of a long freight wagon equipped by Y25 bogies were presented. As evaluated parameters the vertical and the lateral forces and the derailment quotient were assessed. These parameters were evaluated for the tare state and also for the loaded state (max. axle load of $22.5 \mathrm{t}$ ) of the freight wagon. The wagon has run on the real track section model. The measured irregularities were applied into the track model. From the calculated values the highest value of derailment quotient was achieved on the guiding wheel of the tare wagon in the first curve. This value is less than the limit value of 1.2 for this track section.

This work was supported by the Cultural and Educational Grant Agency of the Ministry of Education of the Slo-vak Republic in project No. KEGA 077ŽU4/2017: Modernization of the Vehicles and engines study program.

The work was also supported by the project No. APVV-0842-11: Equivalent railway operation load simulator on the roller rig and VEGA No. 1/0558/18: Research of the interaction of a braked railway wheelset and track in simulated operational conditions of a vehicle running in a track on the test stand.

\section{Research-Educational Center of Rail Vehicles} (VVCKV)

\section{References}

1. J. Soukup, J. Skocilas, B. Skocilasova, Assessment of railway wagon suspension characteristics. Mechanical Systems and Signal Processing 89, 67-77 (2017)

2. O. Lunys, S. Dailydka, S. Steisunas, G. Bureika, Analysis of freight wagon wheel failure detection in Lithuanian Railways. Procedia Engineering 134, 6471 (2016)

3. M. Saga, L. Jakubovicova, Simulation of vertical vehicle non-stationary random vibrations considering various speeds. Scientific journal of Silesian University of Technology - Series Transport 84, 113-118 (2014)

4. V. Hauser, O. Nozhenko, K. Kravchenko, M. Loulova, J. Gerlici, T. Lack, Proposal of a steering mechanism for tram bogie with three axle boxes. Procedia Engineering 192, 289-294 (2017)

5. V. Hauser, O. Nozhenko, K. Kravchenko, M. Loulova, J. Gerlici, T. Lack, Impact of three axle boxes bogie to the tram behavior when passing curved track. Procedia Engineering 192, 295-300 (2017)

6. P. Hejma, M. Svoboda, J. Kampo, J. Soukup, Analytic analysis of a cam mechanism. Procedia Engineering 177, 3-10 (2017)

7. P. Baran, P. Št’astniak, P. Kukuča, M. Brezáni, Investigation of kinematic parameters of two nonconventional piston machines with wobble board. MATEC Web of Conferences 157 (2018)

8. J. Soukup, B. Skocilasova, J. Skocilas, Vibration of mechanical system with higher degrees of freedom: solution of the frequency equations. Procedia Engineering 177, 17-24 (2017)

9. A. Falendysh, M. Volodarets, V. Hatchenko, I. Vykhopen, Software analysis for modeling the parameters of shunting locomotive chassis. MATEC Web of Conferences 116 (2017)

10. A. Golubenko, S. Sapronova, V. Tkachenko, Kinematics of point-to-point contact of wheels with a rails. Transport problems 2(3), 55-59 (2007)

11. J. Gerlici, T. Lack, Railway wheel and rail head profiles development based on the geometric characteristics shapes. Wear 271(1-2), 246-258 (2011)

12. J. Gerlici, T. Lack, Contact geometry influence on the rail / wheel surface stress distribution. Procedia Engineering 2(1), 2249-2257 (2010)

13. L. Smetanka, P. Št’astniak, J. Harušinec, Wear research of railway wheelset profile by using 
computer simulation, MATEC Web of Conferences 157 (2018)

14. G. Vaiciunas, G. Bureika, S. Steisunas, Research on metal fatigue of rail vehicle wheel considering the wear intensity of rolling surface. Eksploatacja i Niezawodnosc - Maintenance and Reliability 20(1), 24-29 (2018)

15. V. Tkachenko, S. Sapronova, Steerability of railway vehicles. Transport problems 2(4), 9-16 (2007)

16. A. Falendysh, P. Kharlamov, O. Kletska, N. Volodarets, Calculation of the parameters of hybrid shunting locomotive. Transport Research Procedia 14, 665-671 (2016)

17. J. Gerlici, T. Lack, Rail vehicles brake components test bench utilisation. Applied mechanics and materials. ISSN 1660-9336. Vol. 486, pp. 379-386 (2014).

18. J. Gerlici, T. Lack, J. Harušinec, Realistic simulation of railway operation on the RAILBCOT test stand. Applied mechanics and materials 486, 387-395 (2014)

19. J. Gerlici, T. Lack, J. Harušinec, Development of test stand prototype for rail vehicles brake components testing. Communications - Scientific Letters of the University of Žilina 16(3a), 27-32 (2014)

20. F. Klimenda, J. Kampo, P. Hejma, Vibration measurement of conveyor rollers. Procedia Engineering 136, 198-203 (2016)

21. J. Harušinec, A. Suchánek, M. Loulová, P. Strážovec, Design of a device to simulate environmental influences on the course of brake tests. MATEC Web of Conferences 157 (2018)

22. A. Sapietova, V. Dekys, Dynamic analysis of rotating machines in MSC:ADAMS. Procedia Engineering 136, 143-149 (2016)

23. M. Chalupa, L. Severa, R. Vlach, Vehicle track loading simulation. Proceedings of SPIE - The International Society for Optical Engineering (2012)

24. M. Chalupa, J. Veverka, R. Vlach, Dynamic loading of vehicle track simulation. Engineering Mechanics (2011)

25. J. Gerlici, T. Lack, Modified HHT method for vehicle vibration analysis in time domain utilisation. Applied mechanics and materials 486, 396-405 (2014)

26. A. Suchánek, J. Harušinec, M. Loulová, P. Strážovec, Analysis of the distribution of temperature fields in the braked railway wheel. MATEC Web of Conferences 157 (2018)

27. M. Gorbunov, J. Gerlici, S. Kara, O. Nozhenko, G. Chernyak, K. Kravchenko, T. Lack, New principle schemes of freight cars bogies. Manufacturing Technology 18(2), 233-238 (2018)

28. J. Gerlici, M. Gorbunov, O. Nozhenko, V. Pistek, S. Kara, T. Lack, K. Kravchenko, About creation of bogie of the freight car. Communication - Scientific Letters of the University of Zilina 19(2), 29-35 (2017)

29. T. Lack, J. Gerlici, A modified strip method to speed up the calculation of normal stress between wheel and rail. Applied mechanics and materials 486, 359370 (2014)

30. T. Lack, J. Gerlici, A modified strip method to speed up the tangential stress between wheel and rail calculation. Applied mechanics and materials 486, 371-378 (2014)

31.S. Sapronova, V. Tkachenko, N. Kramar, A. Voron'ko, Regularities of shaping of a wheel profile as a result of deterioration of the rolling surface in exploitation. Transport Problems 3(4), 47-54 (2008)

32. UIC CODE (2009): 518 OR Testing and approval of railway vehicles from the point of view of their dynamic behaviour - Safety - Track fatigue Running behaviour. $4^{\text {th }}$ edition, September 2009

33. T. Skrucany, J. Ponicky, M. Kendra, J. Gnap, Comparison of railway and road passenger transport in energy consumption and $\mathrm{CHG}$ production. Proceedings of the third international conference of traffic and transport engineering, 744-749 (2016)

34. I. Rybicka, J. Caban, J. Vrabel, B. Sarkan, O. Stopka, W. Misztal, Analysis of the safety systems damage on the example of a suburban transport enterprise. Proceedings of XI International Science-Technical Conference Automotive Safety (2018)

35. A. Suchánek, J. Harušinec, M. Loulová, P. Strážovec, Analysis of the distribution of temperature fields in the braked railway wheel. MATEC Web of Conferences 157 (2018)

36. J. Harušinec, A. Suchánek, M. Loulová, P. Strážovec, Design of a device to simulate environmental influences on the course of brake tests. MATEC Web of Conferences 157 (2018) 